\title{
Pengaruh Perencanaan Pajak Terhadap Manajemen Laba pada Perusahaan Manufaktur Subsektor Makanan dan Minuman yang Terdaftar di Bursa Efek Indonesia
}

\author{
*Eva Rusdyanawati, Mahsina, Kusni Hidayati \\ Program Studi Akuntansi Fakultas Ekonomi dan Bisnis \\ Universitas Bhayangkara Surabaya, Indonesia
}

DOI: 10.46821/ekobis.v1i2.32

\begin{abstract}
ABSTRAK
Penelitian ini bertujuan untuk mengetahui pengaruh perencanaan pajak terhadap manajemen laba pada perusahaan manufaktur subsektor makanan dan minuman yang terdaftar di Bursa Efek Indonesia. Jenis penelitian ini adalah penelitian kuantitatif. Populasi dalam penelitian ini adalah perusahaan manufaktur subsektor makanan dan minuman yang terdaftar di Bursa Efek Indonesia periode 2016-2019 sebanyak 25 perusahaan. Teknik pengambilan sampel menggunakan purposive sampling, sehingga diperoleh sampel sebanyak 11 perusahaan dengan data akhir sebanyak 44 laporan keuangan. Sumber data menggunakan data sekunder yang diunduh melalui website www.idx.co.id. Teknik analisis data menggunakan analisis statistik deskriptif, uji asumsi klasik dan uji analisis regresi linear sederhana. Pengujian data menggunakan alat uji Statistical Package for Social Sciences (SPSS) versi 23. Berdasarkan hasil penelitian ini dapat disimpulkan bahwa perencanaan pajak berpengaruh terhadap manajemen laba pada perusahaan manufaktur subsektor makanan dan minuman yang terdaftar di Bursa Efek Indonesia.
\end{abstract}

Kata kunci : Perencanaan Pajak, Manajemen Laba.

The Influence of Tax Planning to the Earnings Management of Manufacturing Company in the Food and Beverages Subsector Listed in Bursa Efek Indonesi

\begin{abstract}
The purpose of this research is to find out the influence of tax planning to the earnings management of manufacturing company in the food and beverages subsector listed in Bursa Efek Indonesia. This research is a quantitative research. The population of this research was 25 manufacturing companies which engage in the field of food and beverages listed in Bursa Efek Indonesia for period 20162019. The researcher collected the sample by using purposive sampling and 11 companies have been selected as a sample with 44 final statement as a final data. In carrying out the data collection, the researcher using secondary data sourced on website www.idx.co.id. The researcher also using desriptive statistics, classical assumptions and simple linear regression as a analysis technique on Statistical Package for Social Sciences (SPSS) 23. The result of this research conclude that tax planning significantly influence on earnings management of manufacturing company in the food and beverages subsector listed in Bursa Efek Indonesia.
\end{abstract}

Keywords : Tax Planning, Earnings Management. 
Vol. 1 No. 22020

\section{PENDAHULUAN}

Hampir seluruh kehidupan perseorangan maupun perkembangan dunia bisnis di Indonesia dipengaruhi oleh ketentuan peraturan perundang-undangan perpajakan (Zain, 2008). Pajak dapat dilihat dari dua sudut pandang yang berbeda. Dari sudut pandang perusahaan, pajak merupakan beban yang akan mengurangi laba bersih perusahaan. Sedangkan dari sudut pandang pemerintah, pajak merupakan salah satu sumber penerimaan penting yang akan digunakan untuk membiayai pengeluaran negara baik pengeluaran rutin maupun pembangunan (Yuniati, 2018). Salah satu tujuan berdirinya perusahaan adalah untuk memperoleh keuntungan atau laba. Dengan tujuan yang ingin diraih oleh manajemen yaitu memperoleh laba yang tinggi, maka membuat pihak manajemen ingin melakukan penegasan dan meringankan beban pajak sekecil mungkin. Dengan begitu pihak manajemen berupaya meminimalisir pembayaran pajak yang disebut dengan perencanaan pajak. Pada umumnya perencanaan pajak mengacu pada transaksi wajib pajak agar utang pajak, baik PPh maupun pajak-pajak lainnya berada dalam jumlah seminimal mungkin, tetapi masih dalam lingkup peraturan perpajakan. Semakin tinggi perencanaan pajak maka semakin besar peluang perusahaan melakukan praktik manajemen laba. Perusahaan yang ingin melaksanakan perencanaan pajak untuk memperkecil beban pajak secara otomatis meninjau labanya, karena laba tersebut merupakan pokok dari pengenaan pajak. Salah satu hal yang biasanya mendorong manajer untuk melakukan tindakan menyimpang dalam menyampaikan dan melaporkan informasi laba tersebut disebut dengan praktik manajemen laba (Wijaya, 2019). Pada umumnya manajemen laba dilakukan untuk memaksimumkan laba agar dapat memenuhi berbagai kepentingan. Pengetahuan tentang manajemen laba memungkinkan untuk meningkatkan manfaat informasi akuntansi, khususnya laporan laba rugi sebagai dasar pengambilan keputusan bagi investor. Berdasarkan uraian penjelasan tersebut maka penulis tertarik untuk mengetahui dan menganalisis tentang "Pengaruh Perencanaan Pajak Terhadap Manajemen Laba Pada Perusahaan Manufaktur Subsektor Makanan dan Minuman yang Terdaftar di Bursa Efek Indonesia".

\section{TINJAUAN PUSTAKA \\ Perencanaan Pajak}

Menurut Pohan (2018:7) perencanaan pajak merupakan proses mengorganisasi usaha wajib pajak orang pribadi ataupun badan usaha yang dapat ditempuh oleh perusahaan dalam koridor ketentuan perpajakan yang berlaku (loopholes) agar perusahaan dapat membayar utang pajaknya baik PPh maupun pajak lainnya dalam jumlah seminimal mungkin. Dalam penelitian ini, perencanaan pajak diukur dengan menggunakan Tax Retention Rate (tingkat retensi pajak) yang merupakan alat untuk menganalisa suatuukuran dari tingkat efektifitas manajemen pajak yang dilakukan pada laporan keuangan perusahaan tahun berjalan (Wild et al., 2004 dalam jurnal Achyani, 2019).

Tax Retention Rate (TRR) merupakan suatu ukuran efektifitas dari manajemen pajak pada laporan keuangan perusahaan. TRR yang tinggi menandakan perencanaan pajak yang tinggi. Hal ini menandakan bahwa jika TRR yang tinggi, perencanaan pajak pada suatu perusahaan yang dilakukan semakin efektif. Sebaliknya, jika TRR rendah maka perencanaan pajak yang dilakukan perusahaan kurang efektif (Erawati, 2019 dikutip dari Santi, 2018). 
Vol. 1 No. 22020

\section{Manajemen Laba}

Menurut Sulistyanto (2014:6) secara umum manajemen laba didefinisikan sebagai upaya manajer perusahaan untuk mengintervensi atau mempengaruhi informasiinformasi dalam laporan keuangan dengan tujuan untuk mengelabui stakeholder yang ingin mengetahui kinerja dan kondisi perusahaan. Dalam penelitian ini manajemen laba diukur menggunakan discretionary accruals dan dihitung dengan Modified Jones Model (1995) (Sulistiawan, 2011:72). Pengukuran discretionary accruals sebagai indikator manajemen laba dapat dijabarkan dalam tahap-tahap berikut:

a. Menentukan nilai total akrual.

b. Menentukan nilai parameter $\beta_{1}, \beta_{2}$, dan $\beta_{3}$. Lalu, untuk menskala data, semua variabel tersebut dibagi dengan aset tahun sebelumnya (Ait-1).

c. Menghitung nilai NDA.

d. Menentukan nilai akrual diskresioner yang merupakan indikator manajemen laba akrual dengan cara mengurangi total akrual dengan akrual non diskresioner.

\section{Teori Keagenan (Agency Theory)}

Hubungan perencanaan pajak dalam praktik manajemen laba secara konseptual dapat dijelaskan dalam teori keagenan (agency theory). Teori keagenan ini pertama kali diungkapkan oleh Jensen dan Meckling (1976). Teori tersebut menyatakan bahwa manajemen laba ini muncul karena adanya perbedaan kepentingan antara perusahaan (agent) dengan pemerintah (principal). Perusahaan berupaya membayar pajak seminimal mungkin karena dianggap bahwa dengan membayar pajak berarti mengurangi kemampuan ekonomis perusahaan. Namun bagi pemerintah memerlukan dana dari penerimaan pajak untuk membiayai pengeluaran negara (Endriati, 2017). Perselisihan yang terjadi antara pemerintah yang ingin memungut pajak sebesar-besarnya dari beberapa perusahaan ini menjadikan manajemen perusahaan berfikir ulang untuk melakukan perencanaan pajak agar bisa membayar pajak seminimal mungkin sehingga laba perusahaan tidak akan berkurang lebih banyak.

Hubungan variabel dalam penelitian ini adalah sebagai berikut:

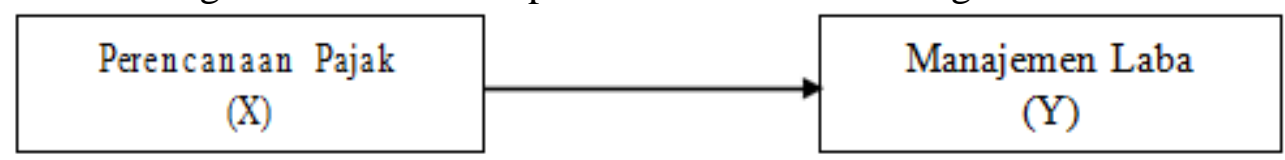

\section{Gambar 1 \\ Kerangka Konseptual}

\section{METODE PENELITIAN}

Jenis penelitian ini merupakan penelitian kuantitatif dengan menggunakan data sekunder yang diperoleh melalui website www.idx.co.id. Populasi dalam penelitian ini adalah perusahaan manufaktur subsektor makanan dan minuman yang terdaftar di Bursa Efek Indonesia periode 2016-2019 sebanyak 25 perusahaan. Teknik pengambilan sampel menggunakan metode purposive sampling, sehingga diperoleh sampel sebanyak 11 perusahaan dengan data akhir sebanyak 44 data laporan keuangan. Teknik analisis data menggunakan Uji Analisis Statistik Deskriptif, Uji Normalitas, Uji Heteroskedastisitas, Uji 
Vol. 1 No. 22020

Autokorelasi dan Uji Analisis Regresi Linear Sederhana. Pengujian hipotesis menggunakan Uji t.

\section{HASIL ANALISIS DAN PEMBAHASAN}

\section{Uji Analisis Statistik Deskriptif}

Berdasarkan tabel 1, dapat disimpulkan bahwa tingkat perencanaan pajak terendah pada tahun 2018 sebesar 0,666 dan tingkat perencanaan pajak tertinggi pada tahun 2016 sebesar 0,874 dengan nilai rata-rata sebesar 0,74750 . Tingkat manajemen laba terendah pada tahun 2016 sebesar -0,034 dan tingkat manajemen laba tertinggi pada tahun 2017 sebesar 0,024 dengan nilai rata-rata sebesar 0,00432.

\section{Uji Normalitas}

Pada tabel 2 dengan sampel penelitian yang berjumlah $\mathrm{N}=44$ menunjukkan bahwa nilai sig 0,001 $<0,05$ maka data tidak berdistribusi normal. Maka dari itu, peneliti melakukan cara lain dengan melakukan transformasi atau di outlier agar variabel penelitian dapat terdistribusi secara normal, sehingga hasil akhir didapatkan $\mathrm{N}=39$ yang dapat dilihat pada tabel 3.

Lalu pada tabel 3 setelah di transformasi atau di outlier dapat diketahui nilai signifikansi sebesar 0,073. Karena nilai sig 0,073>0.05, maka dapat disimpulkan data dalam penelitian ini berdistribusi normal.

\section{Tabel 1}

\section{Hasil Uji Analisis Statistik Deskriptif}

Descriptive Statistics

\begin{tabular}{|c|c|c|c|c|c|}
\hline \multirow{2}{*}{\multicolumn{6}{|c|}{ Perencanaan }} \\
\hline & & & & & \\
\hline Pajak & 44 & 666 & ,874 & ,74750 & 045107, \\
\hline Manajemen Laba & 44 &,- 034 & 024 & 00432 & ,008465 \\
\hline Valid N (listwise) & 44 & & & & \\
\hline
\end{tabular}

Sumber: SPSS versi 23 (Data diolah, 2020)

Tabel 2

Hasil Uji Normalitas

Sebelum Transformasi

One-Sample Kolmogorov-Smirnov Test

\begin{tabular}{|c|c|c|}
\hline & & $\begin{array}{c}\text { Unstandardized } \\
\text { Residual } \\
\end{array}$ \\
\hline $\mathrm{N}$ & & 44 \\
\hline \multirow[t]{2}{*}{ Normal Parameters ${ }^{\mathrm{a}, \mathrm{b}}$} & Mean &, 0000000 \\
\hline & Std. Dev & 00827071 \\
\hline \multirow[t]{3}{*}{ Most Extreme Differences } & Absolute &, 185 \\
\hline & Positive & , 149 \\
\hline & Negative &,- 185 \\
\hline Test Statistic & &, 185 \\
\hline Asymp. Sig. (2-tailed) & &, $001^{\mathrm{c},}$ \\
\hline
\end{tabular}

a. Test distribution is Normal.

b. Calculated from data.

c. Lilliefors Significance Correction.

Sumber: SPSS versi 23 (Data diolah, 2020) 


\section{Tabel 3}

Hasil Uji Normalitas Setelah Transformasi One-Sample Kolmogorov-Smirnov Test

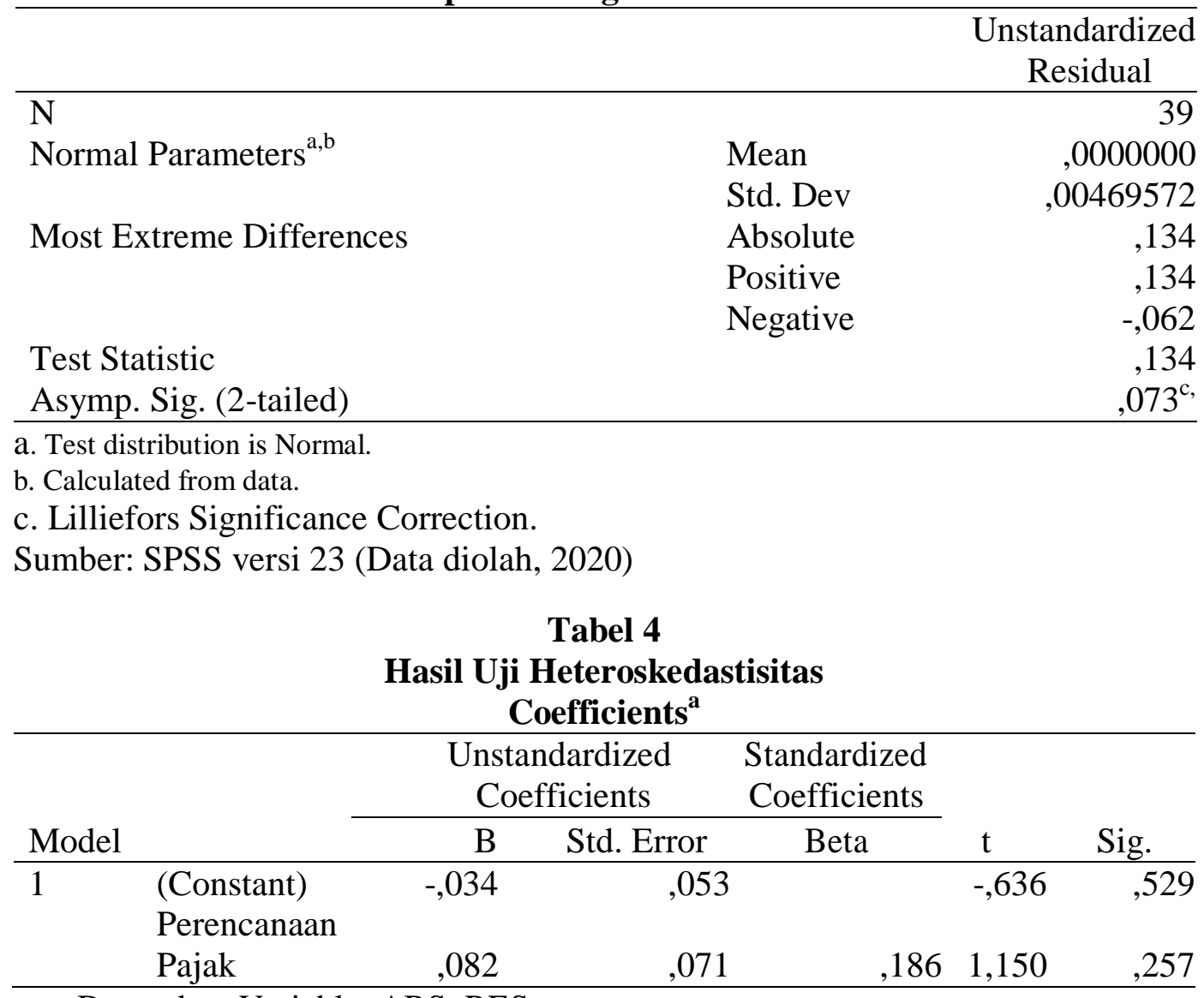

a. Dependent Variable: ABS_RES

Sumber: SPSS versi 23 (Data diolah, 2020)

\section{Uji Heteroskedastisitas}

Berdasarkan tabel 4 hasil pengujian heteroskedastisitas terhadap variabel perencanaan pajak $(X)$ menunjukkan nilai signifikansi 0,257 >0,05 jadi dapat disimpulkan bahwa tidak terjadi heteroskedstisitas dalam model regresi.

\section{Uji Autokorelasi}

Berdasarkan tabel 5 menunjukkan nilai Durbin-Watson yakni sebesar 2,375 dimana nilai ini akan dibandingkan dengan tabel Durbin-Watson yang menggunakan tingkat signifikansi 0,05. Diperoleh nilai batas atas tabel DurbinWatson (du) sebesar 1,5396 dan nilai 4-du =2,4604. Dapat disimpulkan bahwa data penelitian ini terbebas dari autokorelasi karena angka uji Durbin-Watson ada diantara 1,5396 dan $2,4604(1,5396<2,375<2,4604)$.

\section{Uji Analisis Regresi Linear Sederhana}

Koefisien regresi perencanaan pajak sebesar 0,047 menunjukkan bahwa variabel perencanaan pajak mempunyai hubungan searah dengan manajemen laba. Setiap penambahan satu satuan variabel perencanaan pajak dan variabel lainnya konstan, maka manajemen laba akan mengalami kenaikan sebesar 0,047 dan sebaliknya. 


\section{Tabel 5}

Hasil Uji Autokorelasi

Model Summary ${ }^{\text {b }}$

\begin{tabular}{|c|c|c|c|c|c|}
\hline Model & $\mathrm{R}$ & R Square & $\begin{array}{l}\text { Adjusted R } \\
\text { Square }\end{array}$ & $\begin{array}{l}\text { Std. Error of the } \\
\text { Estimate }\end{array}$ & Durbin-Watson \\
\hline 1 & $\underset{\mathrm{a}}{, 374}$ & , 140 & ,116 & ,00476 & 2,375 \\
\hline
\end{tabular}

a. Predictors: (Constant), TRR

b. Dependent Variable: DAit

Sumber: SPSS versi 23 (Data diolah, 2020)

Tabel 6

Hasil Uji Analisis Regresi Linear Sederhana

Coefficients $^{\mathbf{a}}$

\begin{tabular}{|c|c|c|c|c|c|c|}
\hline \multirow[b]{2}{*}{ Model } & & \multicolumn{2}{|c|}{$\begin{array}{l}\text { Unstandardized } \\
\text { Coefficients }\end{array}$} & \multirow{2}{*}{$\begin{array}{c}\text { Standardized } \\
\text { Coefficients }\end{array}$} & \multirow[b]{2}{*}{$\mathrm{t}$} & \multirow[b]{2}{*}{ Sig. } \\
\hline & & $\mathrm{B}$ & Std. Error & & & \\
\hline \multirow[t]{2}{*}{1} & (Constant) &,- 030 &, 014 & & $-2,142$ & ,039 \\
\hline & Perencanaan Pajak & 047 & ,019 &, 374 & 2,451 & ,019 \\
\hline
\end{tabular}

a. Dependent Variable: DAit

Sumber: SPSS versi 23 (Data diolah, 2020)

\section{Tabel 7}

Hasil Uji t

Coefficients $^{\mathrm{a}}$

\begin{tabular}{lllllll}
\hline & \multicolumn{5}{c}{$\begin{array}{c}\text { Unstandardized } \\
\text { Coefficients }\end{array}$} & \multicolumn{2}{c}{$\begin{array}{c}\text { Standardized } \\
\text { Coefficients }\end{array}$} \\
\cline { 2 - 5 } Model & B & Std. Error Beta & t & Sig. \\
\hline 1 & (Constant) &,- 030 &, 014 & & $-2,142,039$ \\
& Perencanaan Pajak, 047 &, 019 &, 374 & 2,451 &, 019 \\
\hline
\end{tabular}

a. Dependent Variable: DAit

Sumber: SPSS versi 23 (Data diolah, 2020)

\section{Uji t}

Berdasarkan tabel 7 hasil uji t menunjukkan bahwa perencanaan pajak yang diukur dengan Tax Retention Rate (TRR) memiliki nilai thitung sebesar 2,451 dan ttabel sebesar 1,68488 yang berarti $t_{\text {hitung }}>t_{\text {tabel }}$ dengan nilai probabilitas signifikansi $0,019<0,05$. Dengan demikian $\mathrm{H}$ diterima dan $\mathrm{H}_{0}$ ditolak, dapat disimpulkan bahwa perencanaan pajak $(\mathrm{X})$ berpengaruh secara signifikan terhadap manajemen laba (Y) pada perusahaan manufaktur subsektor makanan dan minuman yang terdaftar di Bursa Efek Indonesia.

\section{SIMPULAN}

Berdasarkan hasil analisis dan pembahasan tentang pengaruh perencanaan pajak terhadap manajemen laba pada perusahaan manufaktur subsektor makanan dan minuman yang terdaftar di Bursa Efek Indonesia, maka dapat disimpulkan bahwa perencanaan pajak berpengaruh secara signifikan terhadap manajemen laba pada 
perusahaan manufaktur subsektor makanan dan minuman yang terdaftar di Bursa Efek Indonesia selama periode 2016-2019. Karena hasil penghitungan TRR menunjukkan nilai thitung sebesar 2,451 dan ttabel sebesar 1,68488 yang berarti thitung $>$ ttabel dengan nilai signifikansi $0,019<0,05$. sehingga hipotesis $(\mathrm{H})$ dalam penelitian ini diterima. Menurut penulis, hal ini terjadi karena setiap perusahaan pasti menginginkan membayar pajak seminimal mungkin. Salah satu cara yang dilakukan adalah mengatur seberapa besar laba yang dilaporkan, sehingga masuk dalam indikasi adanya praktik manajemen laba. Karena semakin tinggi perencanaan pajak maka semakin besar peluang perusahaan melakukan praktik manajemen laba. Perusahaan yang ingin melakukan perencanaan pajak untuk memperkecil beban pajak otomatis meninjau labanya, karena laba tersebut merupakan pokok dari pengenaan pajak. Berdasarkan dari hasil penelitian yang telah dilakukan, penulis menyadari penelitian ini jauh dari kata sempurna. Oleh sebab itu, untuk penulis selanjutnya dan pihak-pihak lain yang berkepentingan ada beberapa saran yang kedepannya dapat dijadikan sebagai bahan pertimbangan untuk melakukan penelitian dengan topik penelitian yang sama yaitu disarankan pada penelitian selanjutnya lebih baik memperbanyak periode penelitian paling tidak 5 periode agar mendapatkan hasil yang lebih maksimal. Untuk penelitian selanjutnya sebaiknya menambah variabel penelitian, karena masih banyak variabel atau faktor-faktor yang diduga mempengaruhi manajemen laba yang dilakukan oleh perusahaan. Dan untuk penelitian selanjutnya disarankan dapat memperluas sektor perusahaan lainnya seperti pertambangan, perbankan, transportasi, dan lainnya, karena sampel penelitian ini hanya meneliti perusahaan yang bergerak pada subsektor makanan dan minuman saja sehingga hasil penelitian ini tidak dapat digunakan sebagai dasar generalisasi.

\section{DAFTAR PUSTAKA}

Achyani, Fatchan dan Susi Lestari. 2019. "Pengaruh Perencanaan Pajak Terhadap Manajemen Laba (Studi Empiris Pada Perusahaan Manufaktur Yang Terdaftar di Bursa Efek Indonesia)". Jurnal Riset Akuntansi dan Keuangan Indonesia Vol.4 No.1. Fakultas Ekonomi dan Bisnis Universitas Muhammadiyah, Surakarta.

Endriati, Enny, dkk. 2017. "Pengaruh Perencanaan Pajak Terhadap Manajemen Laba Pada Perusahaan Non Manufaktur Yang Terdaftar di Bursa Efek Indonesia”. Fakultas Ekonomi Universitas Islam, Malang.

Erawati, Teguh dan Nurma Ayu Lestari. 2019. "Pengaruh Perencanaan Pajak, Kualitas Audit dan Kepemilikan Institusional Terhadap Manajemen Laba". Jurnal Akuntansi Vol.7 No.1. Fakultas Ekonomi Universitas Sarjanawiyata Tamansiswa, Yogyakarta.

Indonesia Stock Exchange. Laporan Keuangan Perusahaan Tercatat. Dari https://www.idx.co.id/perusahaan-tercatat/laporan keuangan-dan tahunan/

Pohan, Chairil Anwar.2018. Optimizing Corporate Tax Management: Kajian 
Vol. 1 No. 22020

Perpajakan dan Tax Planningnya Terkini Edisi Kedua. Jakarta: Bumi Aksara.

Sulistiawan, Dedhy, dkk 2011. Creative Accounting: Mengungkap Manajemen Laba dan Skandal Akuntasi. Jakarta: Salemba Empat.

Wardani, Dewi Kusuma dan Desifa Kurnia Santi. 2018. "Pengaruh Tax Planning, Ukuran Perusahaan, Corporate Social Responsibility Terhadap Manajemen Laba". Jurnal Akuntansi Vol.6 No.1. Fakultas Ekonomi Universitas Sarjanawiyata Tamansiswa, Yogyakarta.

Wijaya, Ade. 2019. “Analisis Pengaruh Perencanaan Pajak dan Beban Pajak Tangguhan Terhadap Manajemen Laba pada Perusahaan Manufaktur yang Tercatat di Bursa Efek Indonesia. Skripsi. Fakultas Ekonomi Universitas Sriwijaya, Palembang.

Zain, Mohammad. 2008. Manajemen Perpajakan Edisi 3. Jakarta: Salemba Empat. 